\title{
Measuring coronaphobia: the psychological basis of the Coronavirus Anxiety Scale
}

\author{
Sherman A. Lee ${ }^{1 \oplus}$ \\ ${ }^{1}$ Christopher Newport University, Department of Psychology, Newport News, Virginia - USA
}

In January 2020, the World Health Organization declared the COVID-19 disease to be a global public health emergency. Since that time, life around the world has been upended with government-imposed lockdowns, strict social distancing measures, massive school and work closures, and an infection rate nearing 3 million people (1). There have been few events in human history that have caused as much global upheaval and panic as has the COVID-19 outbreak.

As the death toll and hardships due to COVID-19 continue to rise, the number of people who are experiencing elevated and prolonged fear and anxiety appears to be growing as well. For instance, recent reports in the U.S. show that the rate of Americans concerned about coronavirus infection has reached $69.8 \%$ (2), while new prescriptions for anti-anxiety medications grew by $37.7 \%$ (3) and calls to a popular suicide crisis hotline increased to 75 times the amount it normally receives (4). Outside of the U.S., there have been equally disturbing reports of panic attacks in children (5) and suicide among fearful adults (6) due to COVID-19 anxiety. Although research has shown that many people eventually adapt to the threats of a pandemic and become less anxious and afraid, a significant number of people will not adjust and will instead develop long-lasting emotional problems (7).

To help address this growing mental health concern, I created the Coronavirus Anxiety Scale (CAS) (8). The CAS was designed to identify individuals suffering from dysfunctional anxiety about the coronavirus, otherwise known as "coronaphobia," efficiently and effectively (9). The CAS is composed of five somatic-based symptoms of fear and anxiety that are triggered by thoughts or information about the coronavirus (8). Although these emotions presumably have evolved to help humans and other animals attend to and escape from danger, excessive fear and anxiety can be dysfunctional $(10,11)$. It is this heightened emotional experience to coronavirus thoughts or information that the CAS is purported to measure.

Fear is a reactive emotional state triggered by a real or perceived threat that is accompanied by surges of autonomic arousal, thoughts of immediate danger, and escape behaviors (12). Two of the CAS symptoms, dizziness and tonic immobility, seem to capture the physiological reactions of elevated fear to coronavirusrelated stimuli. Not surprisingly, these symptoms are also commonly reported during extremely frightening situations such as in panic attacks and physical assaults $(12,13)$.

Anxiety reflects a generalized anticipation of a future threat (12). Unlike fear, which has a specific focus and is quickly resolved when the threat is gone, anxiety is vague and fades considerably more slowly than fear (10). Anxiety is also accompanied by muscle tension, vigilance for a danger, and avoidant behaviors (12). Two other CAS symptoms, sleep disturbances and appetite loss, seem to capture the physical effects of excessive worry about the coronavirus. Given the extended and unrelenting nature of worry, it is not surprising that these particular symptoms are found in depression as well (12).

The remaining symptom of the CAS appears to capture both fear and anxiety reactions: The experience of nausea or abdominal distress when thinking about or

How to cite this article: Lee SA. Measuring coronaphobia: the psychological basis of the Coronavirus Anxiety Scale. Dusunen Adam The Journal of Psychiatry and Neurological Sciences 2020;33:107-108. 
being exposed to information about the coronavirus can be the result of a fearful reaction or the physical effect of excessive worry, or a combination of both. Because fear and anxiety experiences often overlap (12), the dual quality of this symptom is understandable. Accordingly, this symptom is commonly experienced among those suffering from panic attacks as well as generalized anxiety disorder (12).

Available research suggests that the CAS exhibits solid psychometric and diagnostic qualities. Statistical analyses of the CAS using two independent samples have supported factorial validity and diagnostic accuracy of this mental health screener (14). Specifically, the five CAS symptoms are statistically coherent in providing an internally consistent (Cronbach's as $>0.90$ ) and replicable assessment of the coronaphobia construct. Moreover, ROC analyses of the CAS total scores evidenced strong discrimination ability (AUC values $\geq 0.80$ ), supporting its use as a mental health screener (sensitivity and specificity values $>0.70$ ). The CAS has also repeatedly shown solid construct-related validity including strong correlations with measures of functional impairment, hopelessness, and suicidal ideation $(8,15)$. Taken together, these findings are consistent with previous infectious disease research demonstrating that pandemic-related anxiety has strong implications for people's mental health and well-being (16-18).

As the COVID-19 crisis continues to evolve, future work on the coronaphobia construct should progress and grow as well. A body of empirical research demonstrating the reliability and validity of the CAS is absolutely essential for this instrument to be considered scientifically legitimate and appropriate for clinical use. With coronaphobia being a global mental health threat, cross-cultural studies are also necessary to develop and promote effective treatments and policies counteracting the effects of this pandemic-related anxiety. Finally, studies examining the appropriateness of the CAS for use in specific groups, such as children, and its application using different methods of assessment, such as clinical interviewing, are also important for the advancement of this measure and the study of the coronaphobia construct.

\section{REFERENCES}

1. World Health Organization (2020, April 27). Coronavirus disease (COVID-19) outbreak situation. https://www.who.int/emergencies/ diseases/novel coronavirus-2019. Accessed May 4, 2020.

2. Bycoffe A, Groskopf C, Mehta D. How Americans view the coronavirus crisis and Trump's response. 2020. https://projects. fivethirtyeight.com/coronavirus-polls/ Accessed May 4, 2020.
3. Express Scripts. America's state of mind report. 2020. https:// www.express-scripts.com/corporate/americas-state-of-mindreport. Accessed May 4, 2020.

4. Dunmore R. Coronavirus-related suicides surface amid increased anxiety: hotlines try to provide resources for folks. 2020. https:// newsone.com/3921332/coronavirus-related-suicides-amidanxiety/ Accessed May 4, 2020.

5. Kaba D, Sari BA. Acute stress disorder with panic episodes induced by exposure to COVID-19 outbreak news in a child. Dusunen Adam: The Journal of Psychiatry and Neurological Sciences 2020; 33, doi: 10.14744/DAJPNS.2020.00083. [Epub ahead of print]

6. Goyal K, Chauhan P, Chhikara K, Gupta P, Singh MP. Fear of COVID 2019: First suicidal case in India! Asian J Psychiatr 2020, doi: 10.1016/j.ajp.2020.101989. [Epub ahead of print]

7. Taylor S. The psychology of pandemics: Preparing for the next global outbreak of infectious disease. Newcastle upon Tyne: Cambridge Scholars Publishing, 2019.

8. Lee SA. Coronavirus Anxiety Scale: A brief mental health screener for COVID-19 related anxiety. Death Studies 2020, doi: 10.1080/07481187.2020.1748481. [Epub ahead of print]

9. Asmundson GJG, Taylor S. Coronaphobia: Fear and the 2019nCoV outbreak. J Anxiety Disord. 2020; 70:102196.

10. Kalat JW, Shiota MN. Emotion. Belmont, CA: Thompson Wadsworth, 2007.

11. Ohman A. Fear and anxiety: Evolutionary, cognitive, and clinical perspectives: In Lewis M, J. M. Haviland-Jones (editors). Handbook of emotions. Second Ed. New York: Guilford, 2000, 73-593.

12. American Psychiatric Association. Diagnostic and statistical manual of mental disorders. Fifth Ed. Washington, DC: 2013.

13. Marx BP, Forsyth JP, Gallup GG, Fusé T, Lexington JM. Tonic immobility as an evolved predator defense: Implications for sexual assault survivors. Clinical Psychology: Science and Practice 2008; 15:74-90.

14. Lee SA. Replication analysis of the Coronavirus Anxiety Scale. Dusunen Adam: The Journal of Psychiatry and Neurological Sciences 2020;33. [Epub ahead of print]

15. Lee SA, Jobe MC, Mathis AA. Mental health characteristics associated with dysfunctional coronavirus anxiety. Psychol Med 2020, doi: 10.1017/S003329172000121X. [Epub ahead of print]

16. Taha S, Matheson K, Cronin T, Anisman H. Intolerance of uncertainty, appraisals, coping, and anxiety: the case of the 2009 H1N1 pandemic. Br J Health Psychol 2014; 19:592-605.

17. Wheaton MG, Abramowitz JS, Berman NC, Fabricant LE, Olatunji BO. Psychological predictors of anxiety in response to the H1N1 (swine flu) pandemic. Cognit Ther Res 2012; 36:210218.

18. Wu P, Fang Y, Guan Z, Fan B, Kong J, Yao Z, et al. The psychological impact of the SARS epidemic on hospital employees in China: exposure, risk perception, and altruistic acceptance of risk. Can J Psychiatry 2009; 54:302-311. 